\title{
Saponin-enriched extract of Asparagus cochinchinensis alleviates airway inflammation and remodeling in ovalbumin-induced asthma model
}

\author{
JI-EUN SUNG ${ }^{1}$, HYUN-AH LEE ${ }^{1}$, JI-EUN KIM ${ }^{1}$, WOO-BIN YUN ${ }^{1}$, BEUM-SOO AN ${ }^{1}$, SEUNG-YUN YANG ${ }^{1}$, \\ DONG-SEOB KIM ${ }^{2}$, CHUNG-YEOUL LEE ${ }^{3}$, HEE-SEOB LEE ${ }^{4}$, CHANG-JOON BAE ${ }^{5}$ and DAE-YOUN HWANG
}

\begin{abstract}
Departments of ${ }^{1}$ Biomaterials Science and ${ }^{2}$ Food Science and Technlogy, College of Natural Resources and Life Science/Life and Industry Convergence Research Institute, Pusan National University, Miryang 50463; ${ }^{3}$ Gangrim Organics, Miryang 50455;

${ }^{4}$ Department of Food Science and Nutrition, College of Human Ecology, Pusan National University, Busan 46241;

${ }^{5}$ Biologics Division, Ministry of Food and Drug Safety, Cheongju 28159, Republic of Korea
\end{abstract}

Received September 20, 2016; Accepted September 4, 2017

DOI: $10.3892 / \mathrm{ijmm} .2017 .3147$

\begin{abstract}
Asthma is a chronic inflammatory disease characterized by T-lymphocyte and eosinophil infiltration, mucus overproduction and airway hyper-responsiveness. The present study examined the therapeutic effects and action mechanism of a saponin-enriched extract of Asparagus cochinchinensis (SEAC) on airway inflammation and remodeling in an ovalbumin (OVA)-induced asthma model. To accomplish this, alterations of the nitric oxide (NO) level, inducible nitric oxide synthase (iNOS) and cyclooxygenase-2 (COX-2) expression levels, as well as variations in immune cell numbers, immunoglobulin E ( $\mathrm{IgE}$ ) concentration, histopathological structure and inflammatory cytokine levels were measured in lipopolysaccharide (LPS)-activated RAW264.7 cells or an OVA-induced mouse model of asthma treated with SEAC. The concentration of NO and mRNA levels of COX-2 and iNOS were significantly decreased in the SEAC + LPS-treated RAW264.7 cells compared with the vehicle + LPS-treated RAW264.7 cells. Additionally, in the OVA-induced asthma model, the number of immune cells in the bronchoalveolar lavage fluid, the concentration of OVA-specific IgE, the infiltration of inflammatory cells, the bronchial thickness and the levels of the inflammatory mediators interleukin-4 (IL-4), IL-13 and COX-2 were significantly lower in the OVA + SEAC-treated
\end{abstract}

Correspondence to: Professor Dae-Youn Hwang, Department of Biomaterials Science, College of Natural Resources and Life Science/Life and Industry Convergence Research Institute, Pusan National University, 50 Cheonghak-ri, Samnangjin-eup, Miryang-si, Gyeongsangnam-do 50463, Republic of Korea

E-mail: dyhwang@pusan.ac.kr

Mr Chang-Joon Bae, Biologics Division, Ministry of Food and Drug Safety, 187 Osongsaengmyeong-2-ro, Heungduk-gu, Osong-eup, Cheongju-si, Chungcheongbuk-do 28159, Republic of Korea E-mail: cjbae@korea.kr

Key words: asthma, Asparagus cochinchinensis, ovalbumin, bronchoalveolar lavage fluid, IgE, inflammatory cytokines group compared with the OVA + vehicle-treated group. In addition, a significant reduction in goblet cell hyperplasia, peribronchiolar collagen layer thickness and VEGF expression for airway remodeling was detected in the OVA + SEAC-treated group compared with the OVA + vehicle-treated group. These findings indicate that SEAC is a suppressor of airway inflammation and remodeling, and may therefore be useful as an anti-inflammatory drug for the treatment of asthma.

\section{Introduction}

Asthma is a chronic inflammatory disease of the respiratory airways characterized by recurrent airway obstruction and wheezing (1). The most common features of asthma are airway hyper-responsiveness, the infiltration of eosinophils and T helper 2 (Th2) cells into the airway, and mucus hypersecretion and airway remodeling (1-3). Glucocorticoids have traditionally been used to treat this disease; however, the majority of the drugs administered for its treatment, including glucocorticoids, exhibit side effects such as immunodeficiency, adrenal insufficiency and growth failure, and delayed puberty (4). In addition, glucocorticoids are also ineffective in certain patients. Other treatments such as a monoclonal antibody therapy targeting specific cytokine receptors are being tested in clinical trials, even though the antigenicity of these antibodies in humans requires investigation (5). Therefore, novel treatments based on natural herbs used in traditional medicine are being investigated for their therapeutic efficacy against chronic asthma.

Previous studies have been conducted to generate scientific evidence concerning the anti-inflammatory activity of extracts from Asparagus cochinchinensis (A. cochinchinensis) roots. In one of these studies, the production of pro-inflammatory cytokines and tumor necrosis factor (TNF)- $\alpha$ in lipopolysaccharide (LPS)- and substance P-stimulated mouse astrocytes was found to be significantly inhibited by an aqueous extract of $A$. coch $i$ nchinensis roots (6). In another study, three compounds from an ethanol extract of $A$. cochinchinensis roots decreased the nitric oxide (NO) concentration in LPS-stimulated BV-2 microglial cells (7). The ethanol extract also greatly decreased 
the degree of ectopic edema, ear thickness, cytokine secretion and myeloperoxidase activity, which are considered indicators of skin inflammation progression, in a skin inflammation model of animals treated with 12-O-tetradecanoyl-phorbol13-acetate (TPA) (7). Furthermore, a crude aqueous extract of A. cochinchinensis roots effectively inhibited TNF- $\alpha$-induced cytotoxicity (8), and increased the spleen index and superoxide dismutase activity and decreased the malondialdehyde levels of aged mice (9). Inflammation of the skin of IL-4/Luc/CNS-1 transgenic mice induced by phthalic anhydride treatment was recently successfully suppressed by a saponin-enriched extract of A. cochinchinensis (SEAC) (10). Therefore, the results of previous studies suggest the possibility that the administration of SEAC may effectively inhibit inflammation in various tissues, including those of the lung.

A recent study reported the inhibitory role of $A$. cochinchinensis in allergic asthma-associated airway remodeling, although it was used as only a small part of a combination of complex drugs. In the above study, the standardized herbal formula PM014, which consists of a mixture of $A$. cochinchinensis root and six species of medicinal herbs, efficiently reduced the number of total cells, eosinophils, neutrophils, macrophages and lymphocytes in the bronchoalveolar lavage fluid (BALF) of cockroach allergeninduced mice (11). However, to the best of our knowledge, no studies have shown SEAC to exhibit anti-inflammatory effects in the ovalbumin (OVA)-induced asthma model. Therefore, in the present study, the possibility that SEAC is able to relieve pathological phenotypes including airway inflammation and remodeling was investigated in an OVA-induced asthma model.

\section{Materials and methods}

Preparation of SEAC. The roots of A. cochinchinensis used in this study were obtained from the National Agricultural Cooperation Federation (Gochang, South Korea) and dried in a drying machine (FD5510S-FD5520S; Ilshin Biobase Co., Ltd. Seoul, South Korea) at $60^{\circ} \mathrm{C}$. Voucher specimens of A. cochinchinensis roots (WPC-14-003) were deposited in the functional materials bank of the Wellbeing RIS Center at Pusan National University (Pusan, South Korea). Dried roots were reduced to a powder using a pulverizer (MF-3100S; Hanil Electric Co., Ltd., Seoul, Korea), after which the SEAC was obtained by extraction at $50^{\circ} \mathrm{C}$ for $24 \mathrm{~h}$ using a fixed liquor ratio (ratio of solid powdered A. cochinchinensis to ethyl acetate solvent, 1:10) using circulating extraction equipment (SHWB-30/45; Woori Science Instrument Co., Pocheon, South Korea). These extraction mixtures were subsequently passed through a $0.4-\mu \mathrm{m}$ filter, after which they were concentrated by vacuum evaporation and lyophilization using circulating extraction equipment (IKA Labortechnik, Staufen, Germany). Finally, the collected SEAC powder was dissolved in $0.5 \%$ Tween-20 solution in distilled water $\left(\mathrm{dH}_{2} \mathrm{O}\right)$ to $400 \mathrm{mg} / \mathrm{kg}$, and then further diluted to the required concentration.

In addition, an aqueous extract of Platycodon grandifloras (AePG; Jangsaeng Doraji Co., Jinju-si, Korea) and dexamethasone (Dex) were used as positive controls. The AePG was obtained by extraction of $P$. grandifloras at $120^{\circ} \mathrm{C}$ for $45 \mathrm{~min}$ using a fixed liquor ratio (solid powdered $P$. grandifloras: $\mathrm{dH}_{2} \mathrm{O}$ ratio, $75 \mathrm{~g}: 500 \mathrm{ml}$ ) using circulating extraction equipment (SHWB-30/45). Dex was purchased from Sigma-Aldrich (Merck KGaA, Darmstadt, Germany).
Determination of total saponin, phenolic and flavonoid contents. The total phenolic contents of the SEAC were determined using the Folin-Ciocalteu method as previously described (12). Briefly, a mixture of SEAC solution (1 ml) and Folin-Ciocalteu reagent $(5 \mathrm{ml}$; Sigma-Aldrich; Merck $\mathrm{KGaA}$ ) was incubated at room temperature for $5 \mathrm{~min}$. This mixture was subsequently added to $15 \mathrm{ml} 20 \% \mathrm{Na}_{2} \mathrm{CO}_{3}$ and vortexed for $30 \mathrm{sec}$, after which the absorbance was repeatedly measured at $765 \mathrm{~nm}$ using a VersaMax plate reader (Molecular Devices, LLC, Sunnyvale, CA, USA). A standard calibration curve was generated using different concentrations of gallic acid (Sigma-Aldrich; Merck KGaA), and the concentration of the total phenolic compounds in the SEAC was presented as the gallic acid equivalent $(\mathrm{mg}$ ) of the extract.

The flavonoid contents in the SEAC were measured as previously described (13). In brief, 20- $\mu$ l samples of several different concentrations of SEAC were mixed with $60 \mu 15 \% \mathrm{NaNO}_{2}$ and $60 \mu 110 \% \mathrm{AlCl}_{3}$ (both from Sigma-Aldrich; Merck KGaA). Following incubation at $25^{\circ} \mathrm{C}$ for $5 \mathrm{~min}$, the absorbance was measured using a VersaMax plate reader. A standard calibration curve was then created using different concentrations of catechin (Sigma-Aldrich; Merck KGaA). The flavonoid contents of the SEAC are presented as catechin equivalents (mg) of the extract.

Finally, the total saponin content was determined using the method previously described by Helaly et al (14). The SEAC (5 g) was dissolved in $0.5 \mathrm{ml} 80 \%$ methanol, and then mixed with $0.5 \mathrm{ml} 8 \%$ vanillin in ethanol and $5 \mathrm{ml} 72 \% \mathrm{H}_{2} \mathrm{SO}_{4}$ in water. These mixtures were placed in a $60^{\circ} \mathrm{C}$ water bath for $20 \mathrm{~min}$, and then cooled at $0^{\circ} \mathrm{C}$ for $5 \mathrm{~min}$, after which the absorbance was measured at $544 \mathrm{~nm}$ using a VersaMax plate reader. The saponin content was calculated from a calibration curve constructed using a purified saponin standard (SigmaAldrich; Merck KGaA).

Free radical scavenging activity. The scavenging activity was evaluated using 2,2-diphenyl-1-picrylhydrazyl (DPPH) radicals as previously described (15). In brief, a 100- $\mu 1$ sample comprising one of eleven different concentrations of SEAC (0, 7.8, 15.6, 31.3, 61.5, 125, 250, 500, 1,000, 1,500 and 2,000 $\mu \mathrm{g} / \mathrm{ml})$ was mixed with $100 \mu \mathrm{l} \mathrm{DPPH}(0.1 \mathrm{mM}$; SigmaAldrich; Merck KGaA) in 95\% ethanol solution or $100 \mu 195 \%$ ethanol solution as a control, and then incubated for $30 \mathrm{~min}$ at room temperature. The absorbance of the reaction mixture was subsequently measured at $517 \mathrm{~nm}$ using a VersaMax plate reader. The DPPH radical scavenging activity of the SEAC was expressed as the percentage reduction in absorbance relative to the control. The half maximal inhibitory concentration $\left(\mathrm{IC}_{50}\right)$ was calculated as the concentration of substrate that caused a $50 \%$ loss in DPPH activity.

In vitro assay using RAW264.7 cells. The RAW264.7 cell line used in the present study is an Abelson murine leukemia virustransformed macrophage cell line. The RAW264.7 cells were provided by the Korean Cell Line Bank (Seoul, Korea). The RAW264.7 cells were cultured in Dulbecco's modified Eagle's medium (Thermo Fisher Scientific, Inc., Waltham, MA, USA) containing $10 \%$ fetal bovine serum (cat. no. S001-01; Welgene Inc., Gyeongsan, South Korea), L-glutamine, penicillin and streptomycin (Thermo Fisher Scientific, Inc.) in a humidified incubator at $37^{\circ} \mathrm{C}$ with $5 \% \mathrm{CO}_{2}$ and $95 \%$ air. 


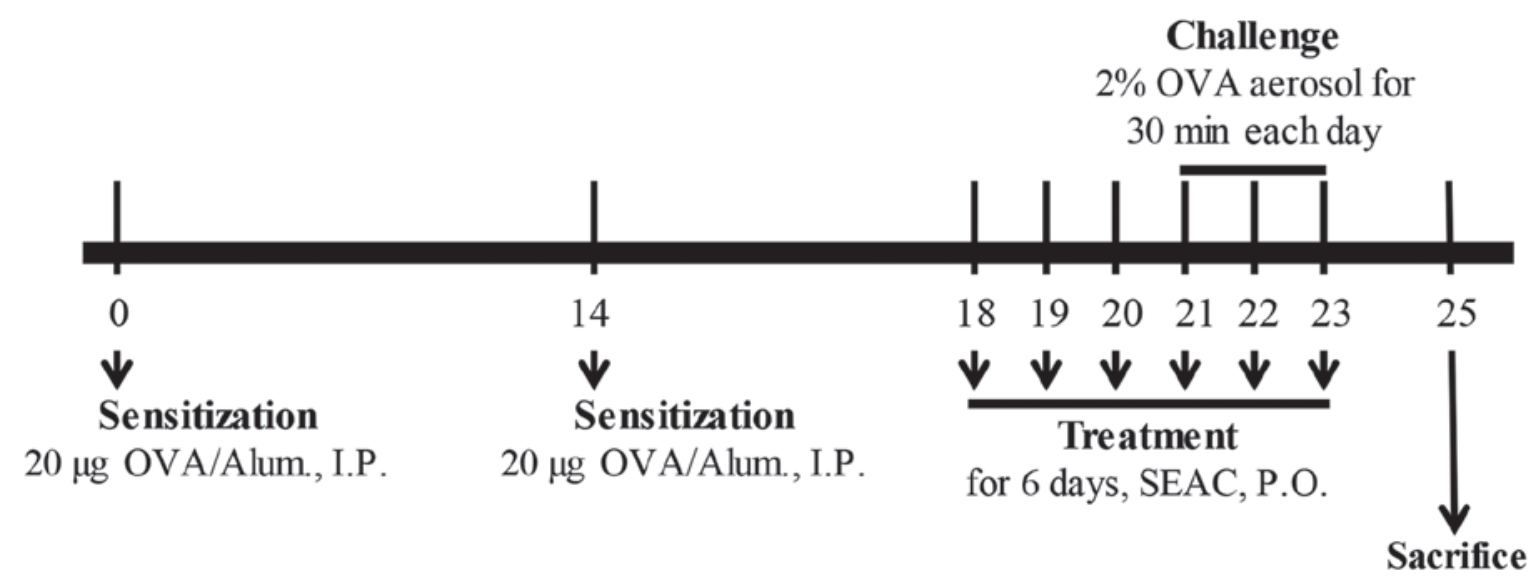

Figure 1. Schedule for sensitization and airway challenge. Balb/c mice were injected i.p. with $20 \mu \mathrm{g}$ OVA and 2 mg Alum on days 0 and 14 for sensitization, and then challenged with the inhalation of 2\% OVA on days 21-23. OVA, ovalbumin; i.p., intraperitoneally; Alum, aluminum hydroxide; SEAC, saponin-enriched extract of Asparagus cochinchinensis.

The accumulation of NO was measured in the culture medium of cells pretreated with the vehicle or SEAC (100 or $200 \mu \mathrm{g}$ / $\mathrm{ml})$ for $2 \mathrm{~h}$ at room temperature followed by LPS $(1 \mu \mathrm{g} / \mathrm{ml})$ for $24 \mathrm{~h}$ using Griess reagent [1\% sulfanilamide, 5\% phosphoric acid and $0.1 \% \mathrm{~N}$-(1-naphthyl) ethylenediamine dihydrochloride; Sigma-Aldrich; Merck KGaA] as described previously (16).

The reactive oxygen species (ROS) levels of cells pretreated with the vehicle or SEAC (100 or $200 \mu \mathrm{g} / \mathrm{ml}$ ) for $2 \mathrm{~h}$ followed by LPS $(1 \mu \mathrm{g} / \mathrm{ml})$ for $24 \mathrm{~h}$ were measured by staining with 2',7'-dichlorodihydrofluorescein (DCFH) diacetate (SigmaAldrich; Merck KGaA), a cell permeable and nonfluorescent agent that is deacetylated by intracellular esterases to form nonfluorescent DCFH, and is converted to highly fluorescent 2',7'-dichlorofluorescein in the presence of intracellular ROS.

The relative expression of inducible nitric oxide synthase (iNOS) and cyclooxygenase (COX)-2 mRNA in RAW264.7 cells that had been pretreated with the vehicle or SEAC (100 or $200 \mu \mathrm{g} /$ $\mathrm{ml})$ for $2 \mathrm{~h}$ followed by LPS $(1 \mu \mathrm{g} / \mathrm{ml})$ for $24 \mathrm{~h}$ were measured by reverse transcription-polymerase chain reaction (RT-PCR) using specific primers as previously described (17).

Animal experimental protocol. The animal protocols used in the present study were reviewed and approved for ethical and scientific care procedures by the Pusan National University-Institutional Animal Care and Use Committee (approval no. PNU-2015-0779). Six-week-old female BALB/c mice were purchased from Samtako Bio Korea Co., Ltd. (Osan, South Korea). Prior to the initiation of the animal experiment, the mice were allowed $\geq 1$ week to adapt to the experimental environment. All mice were provided with ad libitum access to a standard irradiated chow diet (Samtako Bio Korea Co., Ltd.) and water throughout the 25-day study. During the experiment, mice were maintained in a specific pathogen-free state under a strict light cycle (lights on at 08:00 a.m. and off at 20:00 p.m.) at $23 \pm 2^{\circ} \mathrm{C}$ and $50 \pm 10 \%$ relative humidity. The BALB/c mice were housed in the Pusan National University-Laboratory Animal Resources Center accredited by the Korean Ministry of Food and Drug Safety in accordance with the Laboratory Animal Act (accredited unit no. 000231) and AAALAC International according to the National Institutes of Health guidelines (accredited unit no. 001525).
The airway challenge of the BALB/c mice was induced as previously described $(18,19)$. In brief, 6-week-old Balb/c mice (female; $n=48$ ) were assigned to either an untreated group $(n=8)$ or an OVA-treated group $(n=40)$. The untreated group did not receive any treatment during the experimental period. In the other group, OVA-induced asthma was generated by sensitization for 20 days and challenge for 3 days. On days 0 and 14 , the mice were sensitized by the intraperitoneal injection of OVA (albumin from chicken; $20 \mu \mathrm{g}$ ) emulsified with aluminum hydroxide (alum; both from Sigma-Aldrich; Merck KGaA) in $200 \mu 1$ 1X PBS solution. On days 21-23, the mice were subjected to a 30 -min airway challenge with $2 \%$ OVA in 1X PBS by inhalation through a nebulizer (NE-C28; Omron, Tokyo, Japan; Fig. 1). Additionally, the OVA-induced asthma group was further divided into a vehicle-treated group (OVA + vehicle; $n=8)$, Dex-treated group (OVA + Dex; $n=8)$, AePG-treated group (OVA + AePG; n=8), low dose SEAC-treated group (OVA + SEACL; $n=8)$, and high dose SEAC-treated group (OVA + SEACH, n=8). The two $\mathrm{OVA}+\mathrm{SEAC}$-treated groups received 250 and $500 \mathrm{mg} / \mathrm{kg}$ body weight of SEAC, respectively, while the OVA + vehicle group received the same volume $(200 \mu \mathrm{l})$ of $0.5 \%$ Tween-20 solution for 6 days. The therapeutic concentration of SEAC was determined based on the results from previous studies of skin inflammation (10). Furthermore, the OVA + Dex and $\mathrm{OVA}+\mathrm{AePG}$ groups received $3 \mathrm{mg} / \mathrm{kg}$ body weight of Dex solution and $100 \mathrm{mg} / \mathrm{kg}$ body weight of AePG, respectively. At $48 \mathrm{~h}$ after the final treatment, all animals were euthanized using $\mathrm{CO}_{2}$ gas, and tissue samples were acquired and stored in Eppendorf tubes at $-70^{\circ} \mathrm{C}$ until assay.

Enumeration of total cells in BALF. Following anesthesia of the mice with Alfaxan ${ }^{\circledR}$ (alfaxalone; Jurox Pty Ltd., Rutherford, Australia), BALF was obtained (yield, 80\%; total volume, $0.8 \mathrm{ml}$ ) from the mice in each group via tracheal cannulation with cold $1 \mathrm{X}$ PBS. Total cells were then harvested from the BALF by centrifugation $(2,000 \mathrm{xg})$ at $4^{\circ} \mathrm{C}$ for $5 \mathrm{~min}$, after which they were resuspended in $100 \mu 1$ hematoxylin. The eosinophils, macrophages and total cells in $1 \mathrm{~mm}^{2}$ were counted on glass slides using the Leica Application Suite (Leica Microsystems, Heerbrugg, Switzerland). 
Measurement of body weight and immune organ weight. The body weights of all mice in each group throughout the experimental period were measured using an electronic balance (Mettler Toledo GmbH, Greifensee, Switzerland). The weights of the spleen and thymus were also determined following sacrifice using the electronic balance.

Enzyme-linked immunosorbent assay (ELISA) for interleukin (IL)-4 in the BALF. The concentration of IL-4 in the BALF was determined using an IL-4 ELISA kit (cat.no. 431107; BioLegend, Inc., San Diego, CA, USA) according to the manufacturer's protocol. In brief, following collection of the supernatant from the BALF, the assay buffer $(50 \mu \mathrm{l})$ and the supernatant $(50 \mu \mathrm{l})$ were added to a 96-well plate coated with anti-IL-4 antibody, and incubated for $2 \mathrm{~h}$ at room temperature. Following removal of unbound proteins with wash solution $(0.05 \%$ Tween-20 in PBS, $\mathrm{pH}$ 7.4), $100 \mu \mathrm{l}$ detection antibody solution was added and the samples were incubated for $1 \mathrm{~h}$. After washing, $100 \mu \mathrm{l}$ avidin-horseradish peroxidase (HRP) D solution was added to each well, and the plates were allowed to bind for $30 \mathrm{~min}$. Next, the plate was washed and reacted with $100 \mu$ l substrate solution for $15 \mathrm{~min}$. The reaction was then stopped by the addition of $100 \mu$ l blocking solution, after which the absorbance at $450 \mathrm{~nm}$ was determined with a VersaMax plate reader.

Detection of OVA-specific immunoglobulin E (IgE) concentration. The OVA-specific IgE concentration in the serum of the mice was measured using an ELISA kit (cat. no. 439807; BioLegend, Inc.) according to the manufacturer's protocol. Briefly, wells were washed with washing solution (50 mM Tris, $0.14 \mathrm{M} \mathrm{NaCl}, 0.05 \%$ Tween-20, $\mathrm{pH}$ 8.0) four times, after which assay buffer $(50 \mu \mathrm{l})$ and serum samples $(50 \mu \mathrm{l})$ were added to wells coated with antibody and the plate was incubated with shaking for $2 \mathrm{~h}$ at room temperature. Next, the wells were washed with washing solution, after which $100 \mu$ l detection antibody solution was added and the samples were incubated for $1 \mathrm{~h}$ with shaking. After washing the wells, Avidin-HRP D solution $(100 \mu \mathrm{l})$ was added to each well. The plates were then incubated at room temperature for $30 \mathrm{~min}$, after which the wells were washed and an enzyme reaction was initiated by adding substrate solution and incubating the plates at room temperature in the dark for $15 \mathrm{~min}$. Finally, the reaction was terminated by adding $2 \mathrm{M} \mathrm{H}_{2} \mathrm{SO}_{4}$ solution and the absorbance was measured at $450 \mathrm{~nm}$ using a VersaMax plate reader.

Histopathological analysis. Lung tissues were collected from all mice of the various groups, fixed in $10 \%$ neutral buffered formalin, embedded in paraffin wax, routinely processed, and then sectioned into $4-\mu \mathrm{m}$ slices. The tissue sections on a slide glass were stained with hematoxylin and eosin (H\&E; IHC World, Woodstock, MD, USA) after which they were examined using light microscopy to observe the infiltration of inflammatory cells into the peribronchial region of the lung at x400 magnification. The epithelial thickness and smooth muscle thickness of the bronchial tube were also measured using the Leica Application Suite (Leica Microsystems).

Hyperplasia of goblet cells for mucus production was detected by staining with periodic acid-Schiff. Following deparaffinization and dehydration of lung sections, samples were oxidized in periodic acid solution for $5 \mathrm{~min}$ at room tempera- ture. The lung sections were then washed at warm water and placed in Schiff reagent for $5 \mathrm{~min}$ at room temperature. The sections were then washed with warm tap water, stained with hematoxylin solution (IHC world) for $30 \mathrm{sec}$, and examined by light microscopy to detect goblet cell hyperplasia and subepithelial fibrosis at $\mathrm{x} 400$ magnification. The mucus score was then determined by four independent investigators in a singleblind analysis based on four different random locations using a microscope. The mucus scores were: 0 , no mucus; $1,<5 \%$ of the epithelium; $2,5-10 \%$ of the epithelium; $3,10-20 \%$ of the epithelium; $4,20-30 \%$ of the epithelium; $5,30-40 \%$ of the epithelium

RT-PCR analysis of cytokine mRNA expression. The relative quantities of IL-4 and IL-13 mRNA were measured using RT-PCR. In brief, frozen lung tissue was chopped with scissors and homogenized in RNA-Bee solution (Tel-Test, Inc., Friendswood, TX, USA). Total RNA was then isolated by centrifugation at $15,000 \times \mathrm{g}$ for $15 \mathrm{~min}$, after which the RNA concentration was measured using UV spectroscopy. The expression of the target genes was assessed using RT-PCR with $3 \mu \mathrm{g}$ total RNA from the tissue of each group. The RNA was annealed with $500 \mathrm{ng}$ oligo(dT) 12-18 primer (Invitrogen; Thermo FisherScientific,Inc.) at $70^{\circ} \mathrm{C}$ for $10 \mathrm{~min}$. Complementary DNA, which was used as the template for further amplification, was synthesized from the RNA by the addition of $2 \mathrm{mM}$ dNTPs (Deoxynucleoside Triphosphate set; Roche Diagnostics, Basel, Switzerland) with 200 units of SuperScript ${ }^{\mathrm{TM}}$ II reverse transcriptase (200 U/ $\mu 1$; Invitrogen; Thermo Fisher Scientific, Inc.). PCR was then conducted with the mixture of $2.5 \mu \mathrm{l}$ cDNA, 10 pmol sense and antisense primers $(2.5 \mu \mathrm{l})$, Taq DNA polymerase (0.2 $\mu \mathrm{l}$; Roche Diagnostics), 2 mM dNTP (2.5 $\mu \mathrm{l}$; Deoxynucleoside Triphosphate set; Roche Diagnostics), and $10 \mathrm{X}$ reaction buffer containing $15 \mathrm{mM} \mathrm{MgCl} 2(2.5 \mu \mathrm{l})$, and the reaction mixture was subjected to 28-32 cycles of amplification in a thermal cycler (PerkinElmer, Inc., Waltham, MA, USA). The following temperature cycle was used for PCR: $30 \mathrm{sec}$ at $94^{\circ} \mathrm{C}, 30 \mathrm{sec}$ at $62^{\circ} \mathrm{C}$ and $42 \mathrm{sec}$ at $72^{\circ} \mathrm{C}$. The primer sequences used were as follows: IL-4 sense, $5^{\prime}$-CCA GCT AGT TGT CAT CCT GCT CTT C-3' and antisense, 5'-GTG ATG TGG ACT TGG ACT CAT TCA TGG-3'; IL-5 sense, 5'-GAG AAG GAT GCT TCT GCA CTT GAG-3' and antisense, 5'-CCA CTC TGT ACT CAT CAC ACC AAG G-3'; IL-13 sense, 5'-CCT TAA GGA GCT TAT TGA GGA GCT GAG-3' and antisense, 5'-CAG TTG CTT TGT GTA GCT GAG CAG-3'; $\beta$-actin sense, 5'-TGG AAT CCT GTG GCA TCC ATG AAA C-3' and antisense, 5'-TAA AAC GCA GCT CAG TAA CAG TCC G-3'. Three samples were analyzed in duplicate. The final PCR products were separated on $1 \%$ agarose gel, and then visualized by ethidium bromide staining. The band patterns were detected using a UV-transilluminator (ATTO, Tokyo, Japan) and analyzed Image saver 6 (ATTO).

Western blot analysis. Lung tissue $(50 \mathrm{mg})$ collected from each group was homogenized using PRO-PREP ${ }^{\text {TM }}$ Solution (Intron Biotechnology, Inc., Sungnam, Korea), after which total protein extracts were collected by centrifugation at 13,000 x g for $5 \mathrm{~min}$ at $4^{\circ} \mathrm{C}$. The prepared proteins were subsequently subjected to $10 \%$ sodium dodecyl sulfate-polyacrylamide gel electrophoresis for $2 \mathrm{~h}$ at $100 \mathrm{~V}$, after which they were transferred to a nitrocellulose membrane (GE Healthcare Life Sciences, Little Chalfont, 
Table I. Anti-inflammatory effects of SEAC in RAW264.7 cells.

\begin{tabular}{lcrrr}
\hline & & \multicolumn{3}{c}{ LPS } \\
\cline { 3 - 5 } & & & SEAC & SEAC \\
Variable & No & Vehicle & $(100 \mu \mathrm{g} / \mathrm{ml})$ & $(200 \mu \mathrm{g} / \mathrm{ml})$ \\
\hline NO concentration $(\mu \mathrm{M})$ & $0.032 \pm 0.104$ & $20.747 \pm 0.246^{\mathrm{a}}$ & $18.682 \pm 0.722^{\mathrm{a}}$ & $14.701 \pm 1.067^{\mathrm{a}, \mathrm{b}}$ \\
Relative level of iNOS expression & $1.000 \pm 0.083$ & $4.514 \pm 0.461^{\mathrm{a}}$ & $4.788 \pm 0.358^{\mathrm{a}}$ & $3.061 \pm 0.301^{\mathrm{a}, \mathrm{b}}$ \\
Relative level of COX-2 expression & $1 \pm 0.061$ & $3.217 \pm 1.109^{\mathrm{a}}$ & $2.90 \pm 0.801^{\mathrm{a}}$ & $2.672 \pm 0.724^{\mathrm{a}, \mathrm{b}}$ \\
\hline
\end{tabular}

${ }^{\mathrm{a}} \mathrm{P}<0.05$ vs. the No group; ${ }^{\mathrm{b}}<0.05$ vs. the LPS + vehicle-treated group. SEAC, saponin-enriched extract of Asparagus cochinchinensis; No, untreated; LPS, lipopolysaccharide; NO, nitric oxide; iNOS, inducible nitric oxide synthase; COX-2, cyclooxygenase-2.

$\mathrm{UK}$ ) for $2 \mathrm{~h}$ at $40 \mathrm{~V}$ in transfer buffer $(25 \mathrm{mM}$ Trizma-base, $192 \mathrm{mM}$ glycine and 20\% methanol). Appropriate dilutions of the primary antibodies anti-COX-2 (1:1,000; \#12282; Cell Signaling Technology, Inc., Danvers, MA, USA), anti-vascular endothelial growth factor (anti-VEGF; 1:1,000; \#500-P131; PeproTech, Inc., Rocky Hill, NJ, USA) and anti- $\beta$-actin $(1: 3,000$; \#A5316; Sigma-Aldrich) were added to the membranes and allowed to hybridize overnight at $4^{\circ} \mathrm{C}$. Following removal of the antibodies, the membrane was washed three times in a solution comprising $10 \mathrm{mM}$ Trizma-base $(150 \mathrm{mM} \mathrm{NaCl}$ and $0.05 \%$ Tween-20) for $10 \mathrm{~min}$. The membrane was subsequently incubated with 1:3,000 diluted HRP-conjugated goat anti-rabbit IgG (\#G21234; Invitrogen) for $1 \mathrm{~h}$ at room temperature, after which it was washed again as described above and developed using an enhanced chemiluminescence reagent plus kit (Amersham Biosciences; GE Healthcare Life Sciences). Finally, the results were quantified using an image analysis aystem (Fluorchem FC2; ProteinSimple, San Jose, CA, USA) and expressed as the fold-increase over control values.

Statistical analysis. One-way analysis of variance was used to identify significant differences between the untreated and LPS-treated cell groups or between the untreated and OVA-treated mouse groups. Additionally, differences between the vehicle + LPS-treated group and the SEAC + LPS-treated groups, as well between the OVA + vehicle-treated group and the OVA + Dex, OVA + AePG or OVA + SEAC-treated groups were evaluated using a post hoc Tukey's test of the variance and significance levels. All values were expressed as the mean \pm standard deviation. The statistical analysis was conducted using SPSS for Windows, release 10.10, standard version (SPSS, Inc., Chicago, IL, USA). $\mathrm{P}<0.05$ was considered to indicate a statistically significant difference.

\section{Results}

Distribution and antioxidant activity of the bioactive components of SEAC. As shown Fig. 2A, SEAC contained high concentrations of three bioactive components associated with anti-inflammatory activity. Crude saponins were detected at a high level $(57.2 \mathrm{mg} / \mathrm{g})$ in the SEAC. The concentrations of total phenols and total flavonoids were 88.5 and $102.1 \mu \mathrm{g} / \mathrm{g}$, respectively. Furthermore, the scavenging activity of SEAC for DPPH radicals increased in a dose-dependent manner, with an $\mathrm{IC}_{50}$ of $708.56 \mu \mathrm{g} / \mathrm{ml}$ (Fig. 2B).
Effects of SEAC on NO production, iNOS and COX-2 expression and intracellular ROS content in RAW264.7 cells. To examine the possibility that SEAC had anti-inflammatory properties, alterations in NO concentration, iNOS and COX-2 transcription and intracellular ROS level were measured in LPS-stimulated RAW264.7 cells following SEAC pretreatment. The NO concentration, iNOS and COX-2 expression levels (Table I) were significantly increased and intracellular ROS content was markedly increased in the vehicle + LPS-treated group compared with the untreated group (Fig. 2C) . However, these values decreased in a dose-dependent manner in the cells pretreated with 100 and $200 \mu \mathrm{g} / \mathrm{ml}$ SEAC, although the iNOS level was maintained at a constant level in the low dose SEAC-treated group (Table I). These results provide strong evidence that SEAC pretreatment attenuates various types of inflammation in specific tissue by inhibiting the increase in NO concentration, COX-2 and iNOS mRNA expression and intracellular ROS production.

Effects of SEAC treatment on whole body and immune organ weight. To investigate the toxic effects of SEAC on the whole body and immune-associated organs, the whole body, spleen and thymus weight were measured following SEAC treatment. The body weights of the mice in all groups were maintained at a constant level throughout the experimental period, and no significant differences between groups were observed. Furthermore, similar results were detected for the spleen and thymus weights in response to the inflammatory immune reaction, although insignificant increases in the spleen weights of the OVA + SEAC-treated groups were observed (Fig. 3). These results indicate the absence of toxic effects of SEAC on the whole body, including the immune organs.

Effects of SEAC treatment on the number of eosinophils, macrophages and total cells in the BALF. To examine the suppressive effects of SEAC on the inflammatory response in the BALF, the total numbers of leukocytes, eosinophils and macrophages in the BALF were determined. The number of leukocytes was significantly higher in the OVA + vehicle group compared with the untreated group, reflecting the challenge of airway inflammation with OVA. These results imply that OVA antigen challenge triggers a marked influx of leukocytes into the BALF (Fig. 4A). Treatment with OVA + Dex, OVA + AePG or OVA + SEAC induced a significant reduction in the total number of leukocytes in the BALF when compared with the 
A
B
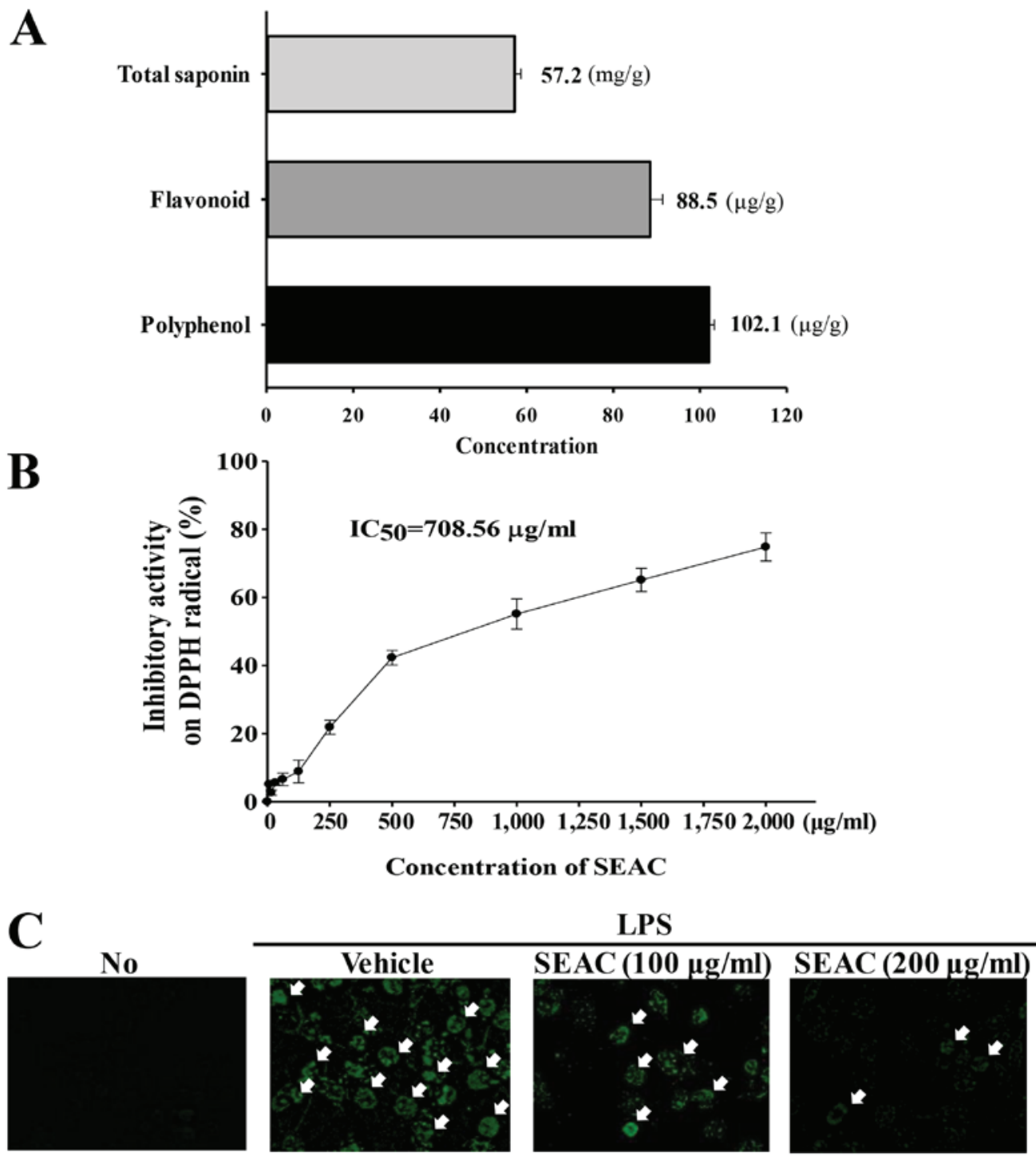

Figure 2. Antioxidant properties of SEAC in RAW264.7 cells. (A) Total saponin, flavonoid and polyphenol concentrations in SEAC. (B) Free radical scavenging activity of SEAC. DPPH radical scavenging activity was assayed in a mixture containing $0.1 \mathrm{mM}$ DPPH and a range of concentrations of SEAC $(250-2,000 \mu \mathrm{g} / \mathrm{ml})$. Values are presented as the means \pm standard deviation of three replicates. (C) Green fluorescence indicating reactive oxygen species in cells was observed using fluorescence microscopy at x200 magnification. Arrows indicate cells stained with DCFH-DA. No, untreated; LPS, lipopolysaccharide; SEAC, saponin-enriched extract of Asparagus cochinchinensis; DPPH, 2,2-diphenyl-1-picrylhydrazyl radical; IC $_{50}$, half maximum inhibitory concentration; DCFH-DA, 2',7'-dichlorodihydrofluorescein diacetate.

OVA + vehicle group (Fig. 4A). A similar pattern of changes was observed for eosinophils and macrophages (Fig. 4A). These findings indicate that SEAC inhibits the inflammatory response of the BALF to OVA inhalation.

Effects of SEAC on the OVA-specific IgE level. The upsurge of inflammatory mediators, including serum $\operatorname{IgE}$, serves as evidence of the onset of asthma $(20,21)$. Therefore, OVA-specific IgE levels were measured in the serum of OVA-sensitized mice treated with vehicle, Dex, AePG or SEAC to evaluate the suppressive effects on IgE production. The OVA-specific IgE level was increased in the OVA + vehicle-treated group compared with the untreated group, suggesting that OVA induction was successful for creation of the asthma model (Fig. 4B). Furthermore, the OVA-specific IgE levels were decreased significantly in the $250 \mathrm{mg} / \mathrm{kg}$ SEAC (OVA + SEACL), $500 \mathrm{mg} / \mathrm{kg}$ SEAC (OVA + SEACH), Dex and AePG treat- ment groups compared with the OVA + vehicle-treated group (Fig. 4B). These results suggest that SEAC treatment successfully reduced OVA-specific IgE levels in the serum.

Effects of SEAC treatment on lung histopathological structure in the OVA asthma model. To discern whether SEAC affects the recovery of pathological structures in the airways, alterations in the histopathological structure of the lungs were evaluated in the OVA + SEAC-treated group. Lung tissue sections from mice that were sensitized with OVA (OVA + vehicle-treated group) displayed a significant expansion in the thickness of the respiratory epithelium and smooth muscle. However, these thicknesses in the OVA + SEACH-treated groups, were significantly decreased compared with those in the OVA + vehicle-treated group. A similar reduction was observed in the infiltration of inflammatory cells in the peribronchiolar region (Fig. 5). These findings demonstrate that SEAC has the potential to 

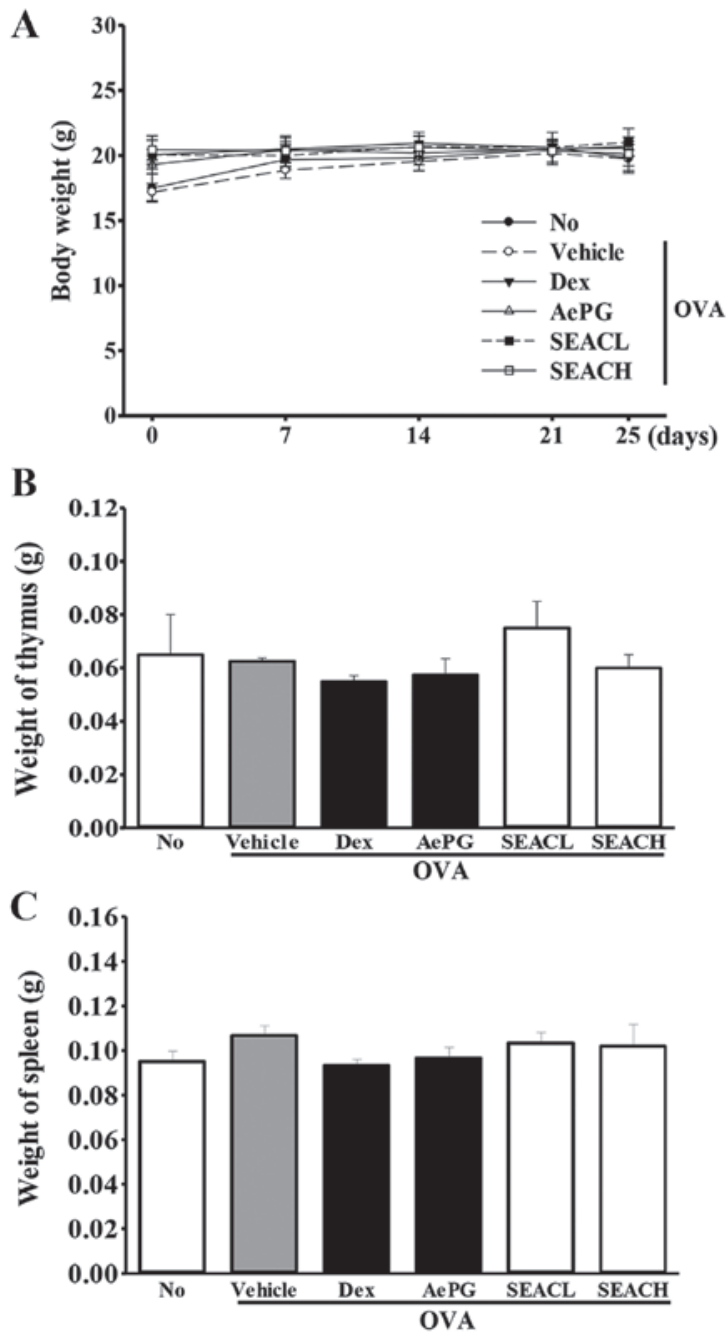

Figure 3. Mouse body and immune organ weights. (A) Body weights were measured in the morning on days 1,7,14,21 and 25.(B and C) Following sacrifice, the spleens and thymuses were harvested from the mice and weighed. Data shown are the mean \pm standard deviation $(n=5)$. No, untreated; OVA, ovalbumin; Dex, dexamethasone; AePG, aqueous extract of Platycodon grandifloras; SEACL, low dose of saponin-enriched extract of Asparagus cochinchinensis; SEACH, high dose of saponin-enriched extract of Asparagus cochinchinensis.

alleviate the histopathological structural changes, including the increased thickness of the respiratory epithelium and smooth muscle, in the airways of the OVA asthma model.

Effects of SEAC on the alteration of inflammatory mediators in the OVA-induced asthma model. The levels of the Th2 cytokines IL-4, IL-5 and IL-13 in the lung were measured using RT-PCR analysis to evaluate differences in the expression of inflammatory mediators among the groups. The transcript levels of these cytokines were higher in the OVA + vehicle-treated group compared with the untreated group. However, the mRNA levels of only IL-4 and IL-13 were significantly decreased in the OVA + SEACH group compared with the OVA + vehicle-treated group (Fig. 6A), while the level of IL-5 mRNA was constantly maintained in the same groups (data not shown). Similar effects were observed in the OVA + Dex and OVA + AePG-treated groups (Fig. 6A). Furthermore, to verify whether these changes at the transcriptional level were maintained at the translational level, IL-4 was selected as one
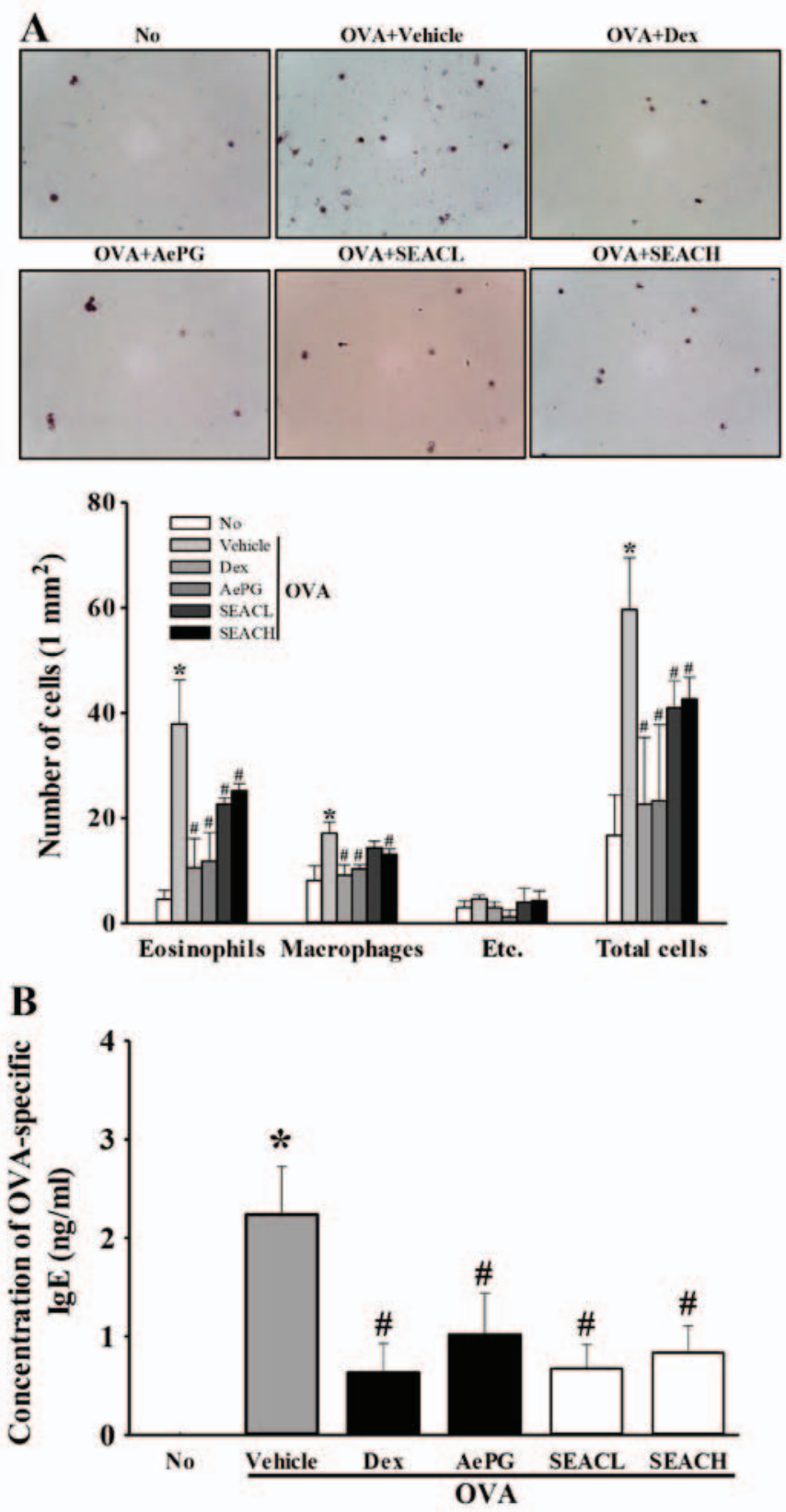

Figure 4. Number of inflammatory cells in BALF and OVA-specific IgE levels in serum. (A) Cells in the BALF were isolated by centrifugation, then stained with hematoxylin. The total number of leukocytes, eosinophils and macrophages was determined by counting within $1 \mathrm{~mm}^{2}$ under a light microscope at $\mathrm{x} 400$ magnification. Etc., lymphocytes and neutrophils. (B) Serum was prepared from blood samples collected from the abdominal veins of mice. The serum concentration of OVA-specific IgE was quantified using an enzyme-linked immunosorbent assay. Data shown are the mean \pm standard deviation $(n=5)$. ${ }^{*} \mathrm{P}<0.05$ vs. the No group; ${ }^{~} \mathrm{P}<0.05$ vs. the OVA + vehicle-treated group. BALF, bronchoalveolar lavage fluid; OVA, ovalbumin; IgE, immunoglobulin E; No, untreated; Dex, dexamethasone; AePG, aqueous extract of Platycodon grandifloras; SEACL, low dose of saponin-enriched extract of Asparagus cochinchinensis; SEACH, high dose of saponin-enriched extract of Asparagus cochinchinensis.

of the key mediators and the protein level of this protein was measured in the BALF. The reduction of IL-4 mRNA detected in the OVA + SEACH group was also observed for IL-4 protein, although the extent of the reduction differed (Fig. 6B).

The expression of another inflammatory mediator, COX-2, was measured in the lung tissue of the OVA + SEAC-treated 

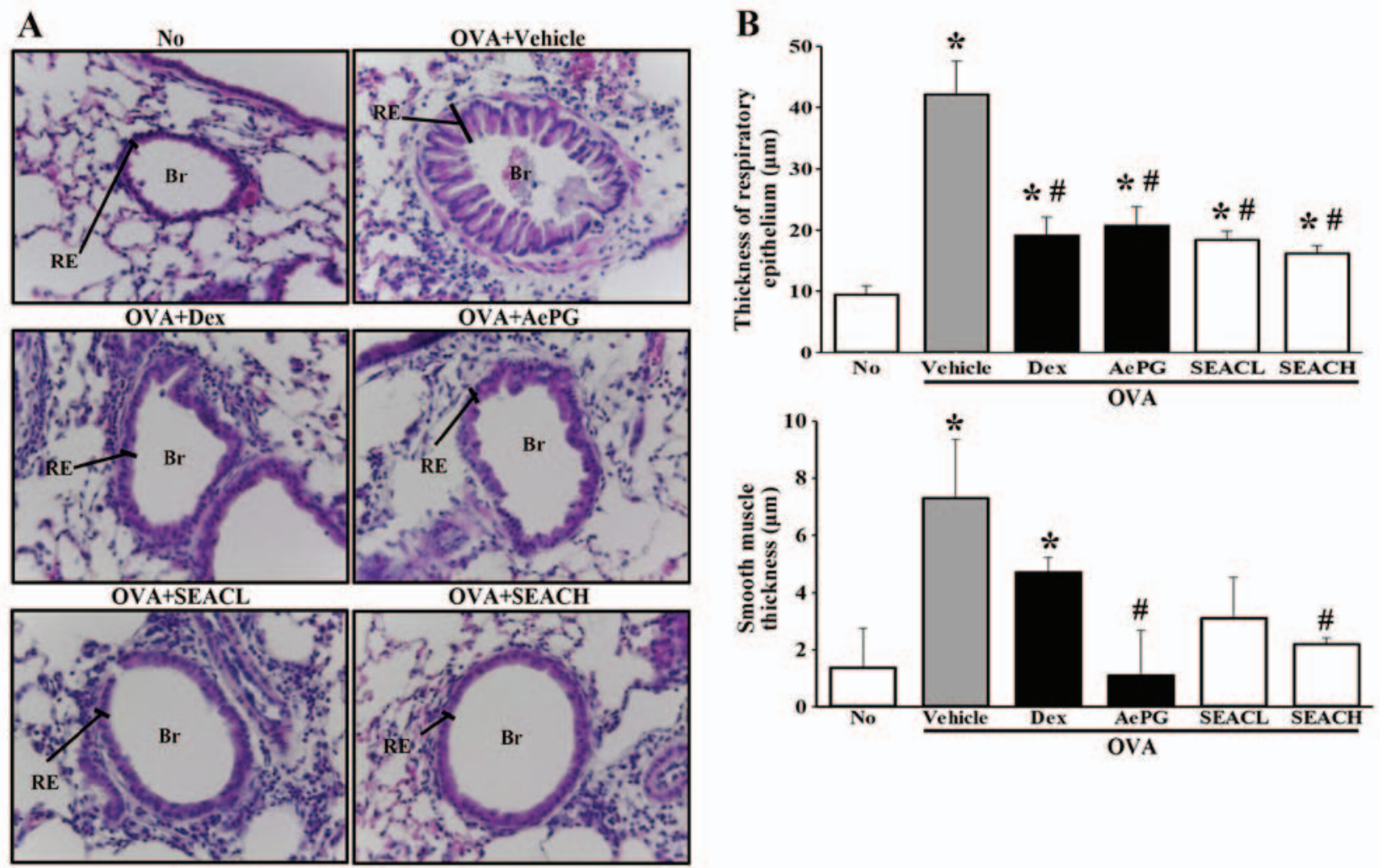

Figure 5. Histopathology of lung tissue. (A) Following staining with hematoxylin and eosin, the infiltration of inflammatory cells in the peribronchiolar region and the bronchial thickness were observed in lung tissue at x400 magnification. (B) Thickness of the respiratory epithelium and smooth muscle was measured using the Leica Application Suite. Data shown are the mean \pm standard deviation $(\mathrm{n}=5)$. ${ }^{*} \mathrm{P}<0.05$ vs. the No group; ${ }^{*} \mathrm{P}<0.05$ vs. the OVA + vehicle-treated group. Br, Bronchus; RE, respiratory epithelium; No, untreated; OVA, ovalbumin; Dex, dexamethasone; AePG, aqueous extract of Platycodon grandifloras; SEACL, low dose of saponin-enriched extract of Asparagus cochinchinensis; SEACH, high dose of saponin-enriched extract of Asparagus cochinchinensis.

group. The level of COX-2 protein in the OVA + vehicle-treated group was significantly higher than that of the untreated group. However, COX-2 levels were significantly reduced in the OVA + SEACL and OVA + SEACH groups compared with the OVA + vehicle-treated group, and these reductions were slightly dependent on the concentration of SEAC (Fig. 7). These results indicate that SEAC is able to inhibit the production of inflammatory mediators, including several cytokines and COX-2 in the lung tissue and BALF.

Inhibitory effects of SEAC on airway remodeling in the OVA-induced asthma model. To determine the effect of SEAC on airway remodeling, measurements of goblet hyperplasia, the thickness of the peribronchiolar collagen layer and VEGF expression levels were made in the OVA-sensitized mice treated with SEAC. A high mucus score indicative of goblet cell hyperplasia was observed in the bronchial airways of mice that were sensitized with OVA (OVA + vehicle-treated group). However, the mucus scores in the OVA +SEACL and $\mathrm{OVA}+\mathrm{SEACH}$-treated groups were significantly lower than that in the OVA + vehicle-treated group (Fig. 8).

Similar results were observed for the thickness of the peribronchiolar collagen layer and subepithelial fibrosis, as may be expected, since collagen deposition in the airways is associated with severe asthma and a reduction in pulmonary function (22) (Fig. 9A and B). In addition, the expression level of VEGF, which is a stimulator of angiogenesis and structural changes in asthma (23), was significantly decreased in the OVA + SEAC-treated groups compared with the OVA + vehicle-treated group (Fig. 9C). These findings demonstrate that SEAC has the potential to stimulate airway remodeling through the regulation of goblet hyperplasia, peribronchiolar collagen layer thickness, subepithelial fibrosis and VEGF expression in the airways of the mouse model of OVA-induced asthma.

\section{Discussion}

Asthma is a chronic respiratory disease characterized by airway inflammation and hyperresponsiveness (1). Although steroids are the drugs most commonly prescribed for asthma, they have a number of adverse effects, including growth inhibition in children (24), cataracts and glaucoma, hypertension, hyperlipidemia, peptic ulcers, myopathy and immunosuppressive effects (25). Accordingly, recent studies have focused on the identification of candidate pharmacologically active ingredients in natural herbs. An approach using natural herbs for the treatment of chronic asthma may enable the reduction of unwanted side effects with long-term drug administration. The present study provides evidence that SEAC acts as an anti-inflammatory and remodeling agent in a mouse model of asthma induced by OVA inhalation. A. cochinchinensis is a perennial herb belonging to the Liliaceae family that is widely grown in China, Japan and Korea, where its roots have been used as a herbal medicine for thousands of years (26). Steroidal saponins and sapogenins, including asparagosides, 
A
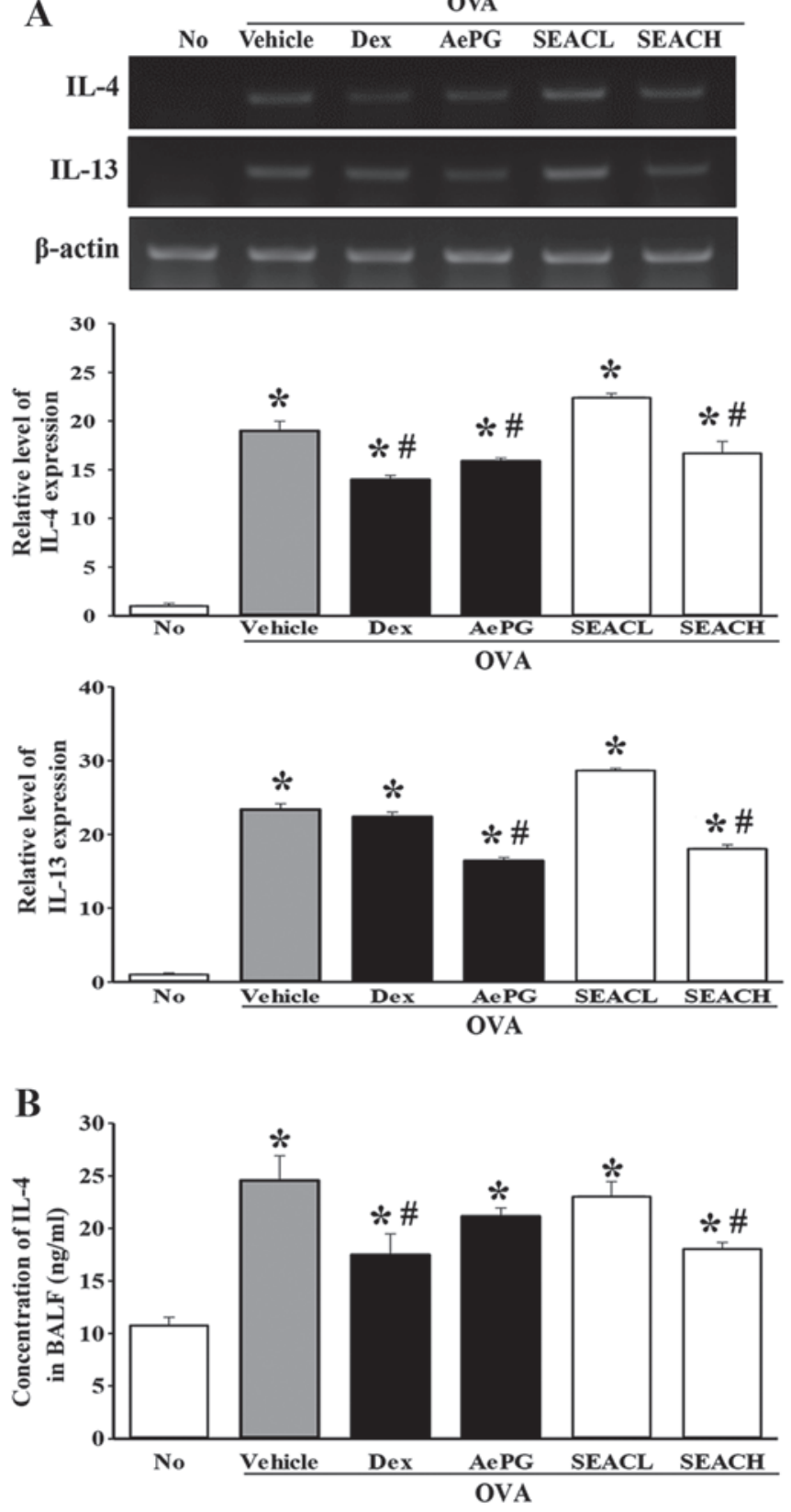

Figure 6. Levels of inflammatory cytokines in lung tissue and BALF. (A) Levels of IL-4 and IL-13 transcripts in the lungs were detected by reverse transcription-polymerase chain reaction analysis using specific primers. The intensity of each band was determined densitometrically and the relative level was calculated based on the intensity of $\beta$-actin transcript as an endogenous control. (B) Following collection of the supernatant from the BALF, IL-4 concentrations were measured using an IL-4 enzyme-linked immunosorbent assay kit with an IL-4 detection limit of $0.5 \mathrm{pg} / \mathrm{ml}$. Data shown are the mean \pm standard deviation $(n=5)$. " $\mathrm{P}<0.05$ vs. the No group; ${ }^{\text {"}} \mathrm{P}<0.05$ vs. the OVA + vehicle-treated group. BALF, bronchoalveolar lavage fluid; IL, interleukin; No, untreated; OVA, ovalbumin; Dex, dexamethasone; AePG, aqueous extract of Platycodon grandifloras; SEACL, low dose of saponin-enriched extract of Asparagus cochinchinensis; SEACH, high dose of saponin-enriched extract of Asparagus cochinchinensis.

furostanol oligosides, asparacosin and sarsasaponen are the major active components of $A$. cochinchinensis roots (27-29). Pharmacological studies of A. cochinchinensis roots have established that they have therapeutic properties, which include immunostimulant activities (9), antioxidant,
A
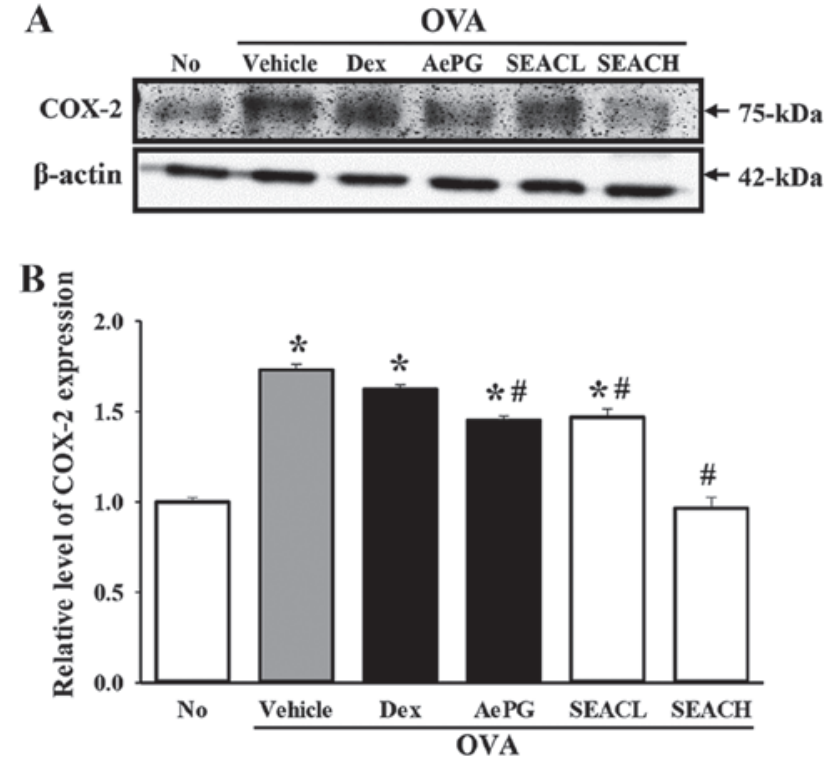

Figure 7. (A and B) Determination of COX-2 expression. Changes in the expression level of COX-2 were examined in the lung tissue using a specific antibody. Data shown represent the mean \pm standard deviation of three replicates. ${ }^{*} \mathrm{P}<0.05$ vs. the No group; ${ }^{\#} \mathrm{P}<0.05$ vs. the OVA + vehicle-treated group. COX, cyclooxygenase; No, untreated; OVA, ovalbumin; DEX, dexamethasone; AePG, aqueous extract of Platycodon grandifloras; SEACL, low dose of saponin-enriched extract of Asparagus cochinchinensis; SEACH, high dose of saponin-enriched extract of Asparagus cochinchinensis.

anti-aging $(26,30,31)$ and antitumor effects $(8,32-34)$ as well as the ability to reduce blood sugar (35) and ameliorate cough (8). Furthermore, A. cochinchinensis is administered in combination with other herbs as a medicine to treat the lungs, spleen, immune system and aging $(9,11,36)$. To identify the specific compounds in SEAC that may exert anti-asthmatic effects, content analysis of saponins, flavonoids and polyphenols was conducted in the present study. A high level of saponins in the SEAC (57.2 $\mu \mathrm{g}$ in $1 \mathrm{~g}$ ) was detected (Fig. 2B). A number of studies have reported that saponins, flavonoids and polyphenols extracted from natural plants exert anti-inflammatory activity (37).

The results of the present study revealed that SEAC led to a notable alleviation of lung inflammation in the OVA-induced mouse model of asthma. These findings were supported by the observed amelioration of various indicators of inflammation in the OVA-induced asthma model mice, which included the weights of immune organs, the number of leukocytes released into the BALF, serum IgE concentration, thickness of the respiratory epithelium, mucus score, and Th2 cytokine and COX-2 expression. These indicators of lung inflammation have been applied in previous studies to investigate the therapeutic effects of various herbal medicines, including Phillinus linteus extract (38), Korean ginseng (39) and KOTMIN13 (40), in OVA-induced asthma models.

The anti-inflammatory activity of A. cochinchinensis ethanol extract (ACE) has previously been investigated in mouse models of skin inflammation (7). In acute and chronic irritant contact dermatitis mouse models, ACE markedly reduced the increase of skin thickness and weight caused by the infiltration of polymorphonuclear leukocytes into the skin of the ear following TPA application (7). In the present study, H\&E 

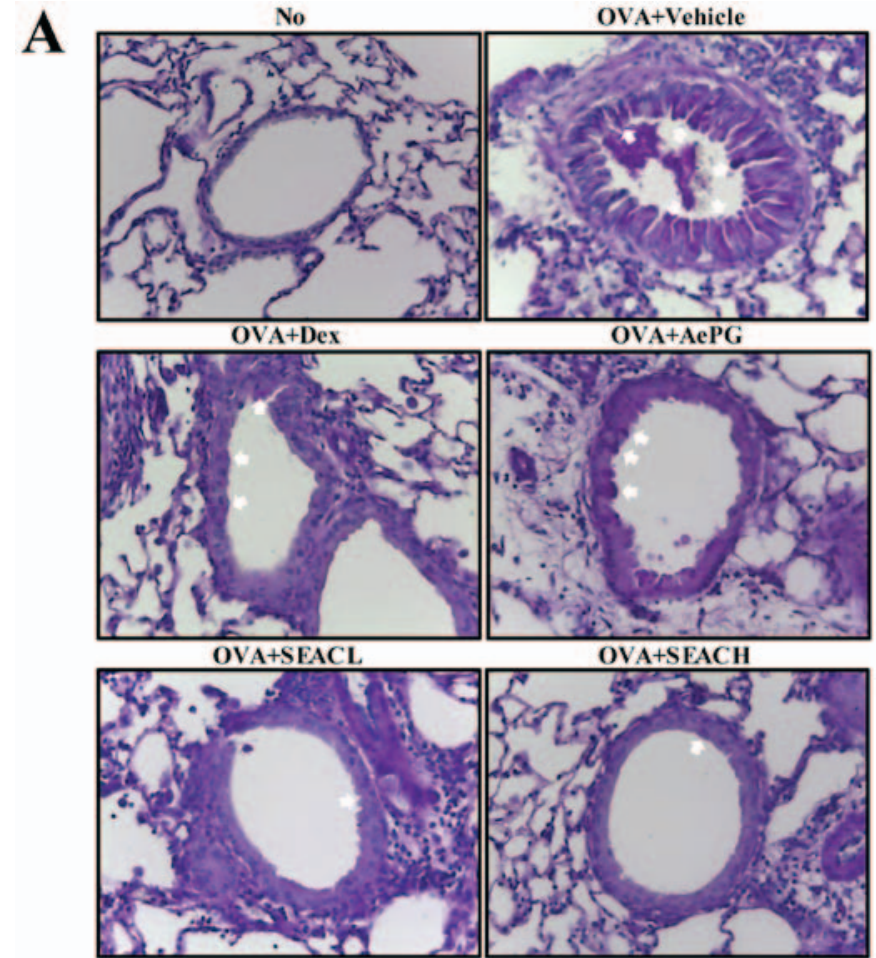

B

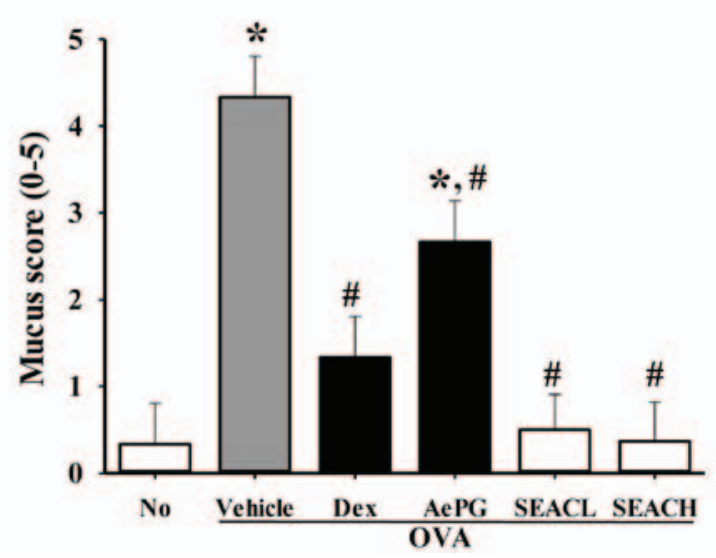

Figure 8. Goblet hyperplasia in lung tissue.(A) Following staining with periodic acid-Schiff, goblet hyperplasia was observed in the lung tissue at x400 magnification. Arrows represent the areas of mucin secretion. (B) Mucus score was determined by four independent investigators based on four different random locations using a microscope. 0 , no mucus; $1,<5 \%$ of the epithelium; $2,5-10 \%$ of the epithelium; 3, 10-20\% of the epithelium; $4,20-30 \%$ of the epithelium; $5,30-40 \%$ of the epithelium. Data shown are the mean \pm standard deviation $(\mathrm{n}=5) .{ }^{*} \mathrm{P}<0.05$ vs. the No group; ${ }^{\prime \prime} \mathrm{P}<0.05$ vs. the OVA + vehicle-treated group. No, untreated; OVA, ovalbumin; Dex, dexamethasone; AePG, aqueous extract of Platycodon grandifloras; SEACL, low dose of saponin-enriched extract of Asparagus cochinchinensis; SEACH, high dose of saponin-enriched extract of Asparagus cochinchinensis.

staining of the lung sections revealed a significant increase in asthmatic indicators, including the thickness of the respiratory epithelium by leukocyte infiltration (Fig. 5) and the levels of mucus secretion (Fig. 8). However, treatment with SEAC led to a clear reduction in those asthmatic indicators, highlighting the potential value of this material for the treatment of asthma.

Alterations in the total cell number of leukocytes, including eosinophils, macrophages and lymphocytes were also
A
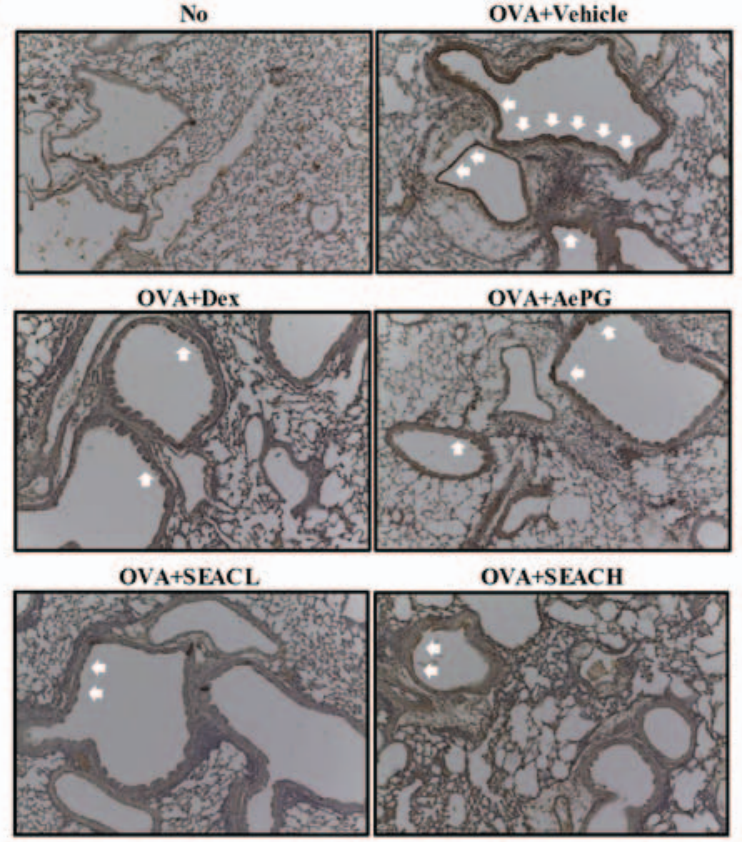

B

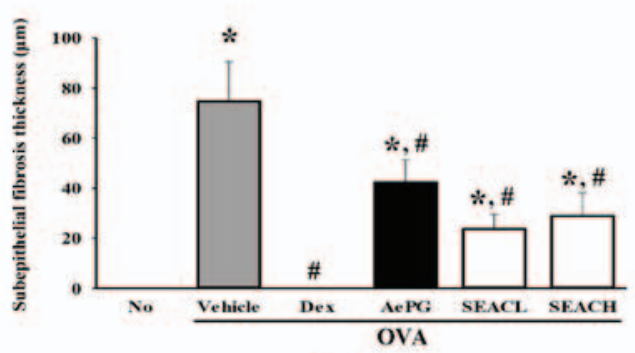

C
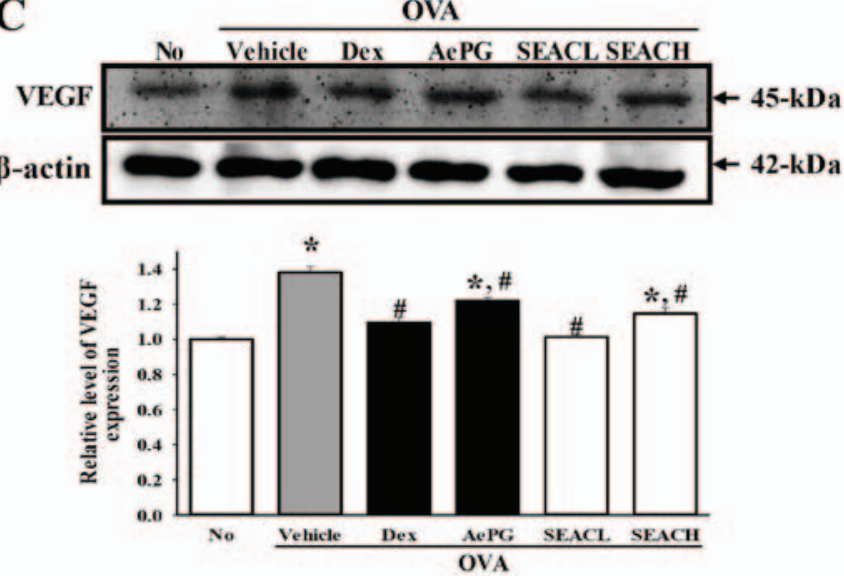

Figure 9. Level of peribronchiolar collagen layer and VEGF expression. (A and B) Following staining with collagen antibody, the collagen levels and subepithelial fibrosis around the airways were observed in lung tissue at $\mathrm{x} 400$ magnification. Arrows show the collagen stained areas. Scale bar, $50 \mu \mathrm{m}$. (C) Changes in the expression levels of VEGF were examined in the lung tissue using specific antibody. Data shown represent the mean \pm standard deviation of three replicates. ${ }^{*} \mathrm{P}<0.05$ vs. the No group; ${ }^{\prime \prime} \mathrm{P}<0.05$ vs. the OVA + vehicle-treated group. No, untreated; OVA, ovalbumin; Dex, dexamethasone; AePG, aqueous extract of Platycodon grandifloras; SEACL, low dose of saponin-enriched extract of Asparagus cochinchinensis; SEACH, high dose of saponin-enriched extract of Asparagus cochinchinensis.

measured in the present study. The influx of eosinophils into the BALF is a major cause of allergic airway inflammation associated with respiratory diseases such as asthma (41). In the 
present study, SEAC treatment reduced the total cell number of leukocytes such as macrophages, eosinophils and lymphocytes in the BALF relative to the OVA + vehicle-treated group. These results suggest that SEAC induces inhibitory effects against airway inflammation. These findings are consistent with the results of previous studies conducted using PM014, a formulation of 18 herbal medicines including A. cochinchinensis, in a mouse model of cockroach allergen-induced asthma (11).

Asthma is a multi-cellular process associated with Th2 cells and leukocytes (42). Th2 cells serve a fundamental role in the regulation of allergic inflammation through the secretion of Th2 cytokines including IL-4, IL-5 and IL-13 (42,43). Among these, IL-4 has multiple effects, including the differentiation of naive $\mathrm{T}$ cells toward the Th2 lineage and the induction of B-cell isotype switching to produce $\operatorname{IgE}$ (44). IL-13 is responsible for various characteristics of Th2 inflammation, particularly in the asthmatic lung, including goblet cell hyperplasia, mucus hypersecretion and bronchial hyperresponsiveness (43). It can also remodel structural cells, including epithelial cells, in the airway, stimulating the expression of proinflammatory factors by airway smooth muscle (45). IL-5 has been suggested to be important for the recruitment of eosinophils and basophil from blood vessels into lung tissue during pulmonary inflammation $(46,47)$. The results of the present study and previous investigations suggest the possibility that $A$. cochinchinensis is able to control the expression of certain inflammatory cytokines. A prior study clearly demonstrated that ACE attenuated the increased secretion of the pro-inflammatory cytokines IL- $1 \beta$ and TNF- $\alpha$ in TPA-induced acute irritant contact dermatitis (7). In another study using the PM014 herbal formulation, the levels of Th2 cytokines IL-4, IL-5 and IL-13 were decreased in the BALF of mice with cockroach allergen-induced asthma (11). Similarly, the levels of the inflammatory mediators IL-4, IL-13 and COX-2 were significantly lower in the lung tissue and BALF of OVA + SEAC-treated mice compared with OVA + vehicle-treated mice in the present study. However, the level of IL-5 mRNA was not significantly reduced in the OVA + SEAC-treated group. It is likely that the detected difference between these studies can be predominantly attributed to the composition of the treatment extracts, the administration conditions and the allergens used to produce the asthma model. Therefore, additional studies are required to understand what other factors determine the therapeutic effects of SEAC and the underlying mechanisms of the asthma model.

Elevated $\operatorname{IgE}$ in the serum is characteristic of asthma (1). In a previous study of the PM014 herbal formulation, the levels of serum IgE in a mouse model of cockroach allergeninduced asthma were decreased (11). In the present study, SEAC exerted prominent inhibitory effects on the levels of serum IgE (Fig. 4B). Accordingly, the administration of SEAC resulted in a marked reduction in serum $\operatorname{IgE}$ levels in the mouse OVA-induced asthma model (Fig. 4B).

Airway remodeling is characterized by several key factors, including collagen deposition, smooth muscle hyperplasia and VEGF expression. In mice subjected to chronic OVA exposure, a marked increase in collagen deposition and enhancement of the $\alpha$-SMA stained area were observed around the airway $(48,49)$. Furthermore, airway remodeling has been indicated to be promoted by epithelial cell-derived VEGF (50). Decreased VEGF expression can lead to a significant reduction in goblet cell hyperplasia and basement membrane thickness (51). Collagen deposition, smooth muscle hyperplasia and VEGF expression have been shown to be significantly inhibited by various natural compounds and extracts, including proanthocyanidin from grape seed extract (52), Bangpungtongseong-san (53), Astragalus extract (54) and ligustrazine (55). In the present study, the administration of SEAC significantly reduced goblet cell hyperplasia, collagen deposition and VEGF expression in the OVA-induced asthma model, although there were some differences in the extent to which they were reduced. These results are very similar to the results reported for various natural products including Bangpungtongseong-san (53) and Astragalus extract (54) in several of the aforementioned previous studies.

The results of the present study suggest that SEAC is a potential candidate for use in the attenuation of inflammation in asthma through the inhibition of OVA-specific IgE production, recovery of histopathological structure and suppression of inflammatory mediators. To the best of our knowledge, this is the first study demonstrating that $A$. cochinchinensis has anti-inflammatory and remodeling activities in the airway of an asthma model. However, additional studies are required to advance our understanding of the effects of SEAC, as well as the mechanisms accountable for these effects.

\section{Acknowledgements}

The present study was supported by a grant to Professor Dae Youn Hwang from the Korea Institute of Planning Evaluation for Technology of Food, Agriculture, Forestry and Fisheries (grant no. 114034-03-1-HD030).

\section{References}

1. Endo Y, Hirahara K, Yagi R, Tumes DJ and Nakayama T: Pathogenic memory type Th2 cells in allergic inflammation. Trends Immunol 35: 69-78, 2014.

2. Rosenberg JL: Antilipid agents may provide allergy protection. Ann Allergy Asthma Immunol 110: 1, 2013.

3. Porter PC, Yang T, Luong A, Delclos GL, Abramson SL, Kheradmand F and Corry DB: Proteinases as molecular adjuvants in allergic airway disease. Biochim Biophys Acta 1810: 1059-1065, 2011.

4. Sousa AR, Lane SJ, Cidlowski JA, Staynov DZ and Lee TH: Glucocorticoid resistance in asthma is associated with elevated in vivo expression of the glucocorticoid receptor $\beta$-isoform. J Allergy Clin Immunol 105: 943-950, 2000.

5. Liu Y, Zhang S, Li DW, Jiang SJ: Efficacy of anti-interleukin-5 therapy with mepolizumab in patients with asthma: a metaanalysis of randomized placebo-controlled trials. PLoS One 8: e59872, 2013.

6. Kim H, Lee E, Lim T, Jung J and Lyu Y: Inhibitory effect of Asparagus cochinchinensis on tumor necrosis factor-alpha secretion from astrocytes. Int J Immunopharmacol 20: 153-162, 1998.

7. Lee DY, Choo BK, Yoon T, Cheon MS, Lee HW, Lee AY and Kim HK: Anti-inflammatory effects of Asparagus cochinchinensis extract in acute and chronic cutaneous inflammation. J Ethnopharmacol 121: 28-34, 2009.

8. Luo J, Long QD, Li CX, Li L, Huang NH, Nie M and Tang PX: Comparison of antitussive, expectorant and anti-asthmatic effect between ALWB and ACM. Guiyang Yi Xue Yuan Xue Bao 23: 132-134, 1998 (In Chinese).

9. Xiong D, Yu LX, Yan X, Guo C and Xiong Y: Effects of root and stem extracts of Asparagus cochinchinensis on biochemical indicators related to aging in the brain and liver of mice. Am J Chin Med 39: 719-726, 2011.

10. Sung JE, Lee HA, Kim JE, Go J, Seo EJ, Yun WB, Kim DS, Son HJ, Lee CY, Lee HS, et al: Therapeutic effect of ethyl acetate extract from Asparagus cochinchinensis on phthalic anhydrideinduced skin inflammation. Lab Anim Res 32: 34-45, 2016. 
11. Jung KH, Choi HL, Park S, Lee G, Kim M, Min JK, Min BI and Bae $\mathrm{H}$ : The effects of the standardized herbal formula PM014 on pulmonary inflammation and airway responsiveness in a murine model of cockroach allergen-induced asthma. J Ethnopharmacol 155: 113-122, 2014.

12. Singleton VL and Rossi JA: Colorimetry of total phenolics with phosphomolybdic-phosphotungstic acid reagents. Am J Enol Vitic 16: 144-158, 1965.

13. Zhishen J, Mengcheng T and Jianming W: The determination of flavonoid contents in mulberry and their scavenging effects on superoxide radicals. Food Chem 64: 555-559, 1999.

14. Helaly FM, Soliman HSM, Soheir AD and Ahmed AA: Controlled release of migration of molluscicidal saponin from different types of polymers containing Calendula officinalis. Adv Polym Technol 20: 305-311, 2001.

15. Oh H, Ko EK, Kim DH, Jang KK, Park SE, Lee HS and Kim YC: Secoiridoid glucosides with free radical scavenging activity from the leaves of Syringa dilatata. Phytother Res 17: 417-419, 2003.

16. Jie S, Xueji Z, Mark B and Harry F: Measurement of nitric oxide production in biological systems by using Griess reaction assay. Sensors (Basel) 3: 276-284, 2003.

17. Kim JE, Park SH, Kwak MH, Go J, Koh EK, Song SH, Sung JE, Lee HS, Hong JT and Hwang DY: Characterization of changes in global genes expression in the distal colon of loperamide-induced constipation SD rats in response to the laxative effects of Liriope platyphylla. PLoS One 10: e0129664, 2015.

18. Jung JY, Lee KY, Lee MY, Jung D, Cho ES and Son HY: Antioxidant and antiasthmatic effects of saucerneol D in a mouse model of airway inflammation. Int Immunopharmacol 11: 698-705, 2011.

19. Zhou E, Fu Y, Wei Z, Yu Y, Zhang X and Yang Z: Thymol attenuates allergic airway inflammation in ovalbumin (OVA)induced mouse asthma. Fitoterapia 96: 131-137, 2014.

20. Platts-Mills TA: The role of immunoglobulin E in allergy and asthma. Am J Respir Crit Care Med 164: S1-S5, 2001.

21. Spina D: Asthma mediators: current views. J Pharm Pharmacol 52: $125-145,2000$

22. Yamauchi $\mathrm{K}$ and Inoue $\mathrm{H}$ : Airway remodeling in asthma and irreversible airflow limitation - ECM deposition in airway and possible therapy for remodeling-. Allergol Int 56: 321-329, 2007.

23. Zha W, Su M, Huang M, Cai J and Du Q: Administration of pigment epithelium-derived factor inhibits airway inflammation and remodeling in chronic OVA-induced mice via VEGF suppression. Allergy Asthma Immunol Res 8: 161-169, 2016.

24. Wise J: Corticosteroids for asthma may suppress growth in children in first year of treatment, researchers say. BMJ 349: g4623, 2014

25. Ciriaco M, Ventrice P, Russo G, Scicchitano M, Mazzitello G Scicchitano F and Russo E: Corticosteroid-related central nervous system side effects. J Pharmacol Pharmacother 4 (Suppl 1): S94-S98, 2013.

26. Qu FY, Wei XD, Li SL, Wang YM and Bai SG: Experimental study of Asparagus cochinchinensis delay aging. Zhong Yi Yao Xue Bao 2: 68-70, 1999 (In Chinese).

27. Konishi T and Shoji J: Studies on the constituents asparagi radix. I. On the structures of furostanol oligosides of Asparagus cochinensis (Loureio) Merrill. Chem Pharm Bull (Tokyo) 27: 3086-3094, 1979.

28. Yang YC, Huang SY and Shi JG: Two new furostanol glycosides from Asparagus cochinchinensis. Chin Chem Lett 13: 1185-1188, 2002.

29. Zhang ZJ: Therapeutic effects of herbal extracts and constituents in animal models of psychiatric disorders. Life Sci 75: 1659-1699, 2004.

30. Li M, Fei Y and Wang JK: Studies on pharmacologic effects of Radix Asparagi. Shizhen Guo Yi Guo Yao 16: 580-582, 2005 (In Chinese).

31. Zhao YJ, Meng XL, Li XL and Qu FY: Influence of Radix Asparagi nano-pharmaceutics on NOS, NO, LPF of senile mice. Zhongguo Ye Sheng Zhi Wu Zi Yuan 24: 49-51, 2005 (In Chinese)

32. Wen JY, Li Y, Ding SS and Li QH: Pharmacological screening of 9 medicinal plants of the genus Asparagus (Liliaceae) in China Shanghai Yi Ke Da Xue Xue Bao 20: 107-111, 1993 (In Chinese)

33. Koo HN, Jeong HJ, Choi JY, Choi SD, Choi TJ, Cheon YS, Kim KS, Kang BK, Park ST, Chang CH, et al: Inhibition of tumor necrosis factor-alpha-induced apoptosis by Asparagus cochinchinensis in Hep G2 cells. J Ethnopharmacol 73: 137-143, 2000.
34. Park M, Cheon MS, Kim SH, Chun JM, Lee AY, Moon BC, Yoon T and Choo BK: Anticancer activity of Asparagus cochinchinensis extract and fraction in HepG2 cells. J Korean Soc Appl Biol Chem 54: 188-193, 2011.

35. Yu FR, Lian XZ and Guo HY: Effect of Lucid asparagus extract on the regulation of blood sugar. Zhongguo Lin Chuang Kang Fu 10: 57-59, 2006 (In Chinese).

36. Xiao PG: Modern Chinese Material Medica. China Press, Beijing, p150, 2002.

37. Huang Y, Cai T, Xia X, Cai Y and Wu XY: Research advances in the intervention of inflammation and cancer by active ingredients of traditional Chinese medicine. J Pharm Pharm Sci 19: 114-126, 2016.

38. Yan GH and Choi YH: Phellinus linteus extract exerts antiasthmatic effects by suppressing NF- $\mathrm{kB}$ and p38 MAPK activity in an OVA-induced mouse model of asthma. Immune Netw 14: 107-115, 2014.

39. Lim CY, Moon JM, Kim BY,Lim SH, Lee GS, Yu HS and Cho SI: Comparative study of Korean White Ginseng and Korean Red Ginseng on efficacies of OVA-induced asthma model in mice. J Ginseng Res 39: 38-45, 2015.

40. Lee E, Kim SG, Park NY, Park HH, Jeong KT, Choi J, Lee IH, Lee H, Kim KJ and Lee E: KOTMIN13, a Korean herbal medicine alleviates allergic inflammation in vivo and in vitro. BMC Complement Altern Med 16: 169, 2016.

41. Kay AB: Asthma and inflammation. J Allergy Clin Immunol 87: 893-910, 1991.

42. Ngoc PL, Gold DR, Tzianabos AO, Weiss ST and Celedón JC: Cytokines, allergy, and asthma. Curr Opin Allergy Clin Immunol 5: 161-166, 2005.

43. Larché M, Robinson DS and Kay AB: The role of T lymphocytes in the pathogenesis of asthma. J Allergy Clin Immunol 111: 450-464, 2003.

44. Li-Weber M and Krammer PH: Regulation of IL4 gene expression by $\mathrm{T}$ cells and therapeutic perspectives. Nat Rev Immunol 3: 534-543, 2003

45. Zheng W and Flavell RA: The transcription factor GATA-3 is necessary and sufficient for Th2 cytokine gene expression in CD4 T cells. Cell 89: 587-596, 1997.

46. Sedgwick JB, Calhoun WJ, Gleich GJ, Kita H, Abrams JS, Schwartz LB, Volovitz B, Ben-Yaakov M and Busse WW: Immediate and late airway response of allergic rhinitis patients to segmental antigen challenge. Characterization of eosinophil and mast cell mediators. Am Rev Respir Dis 144: 1274-1281, 1991.

47. Greenfeder S, Umland SP, Cuss FM, Chapman RW and Egan RW: Th2 cytokines and asthma. The role of interleukin-5 in allergic eosinophilic disease. Respir Res 2: 71-79, 2001.

48. Makinde T, Murphy RF and Agrawal DK: The regulatory role of TGF-beta in airway remodeling in asthma. Immunol Cell Biol 85: 348-356, 2007.

49. Martin JG, Duguet A and Eidelman DH: The contribution of airway smooth muscle to airway narrowing and airway hyperresponsiveness in disease. Eur Respir J 16: 349-354, 2000.

50. Lopez-Guisa JM, Powers C, File D, Cochrane E, Jimenez N and Debley JS: Airway epithelial cells from asthmatic children differentially express proremodeling factors. J Allergy Clin Immunol 129: 990-7.e6, 2012.

51. Yuksel H, Yilmaz O, Karaman M, Bagriyanik HA, Firinci F, Kiray M, Turkeli A and Karaman O: Role of vascular endothelial growth factor antagonism on airway remodeling in asthma. Ann Allergy Asthma Immunol 110: 150-155, 2013.

52. Zhou DY,Fang SR,Zou CF, Zhang Q and Gu W: Proanthocyanidin from grape seed extract inhibits airway inflammation and remodeling in a murine model of chronic asthma. Nat Prod Commun 10: 257-262, 2015.

53. Lee MY, Shin IS, Jeon WY, Shin N and Shin HK: Bangpungtongseong-san, a traditional herbal medicine, attenuates chronic asthmatic effects induced by repeated ovalbumin challenge. Int J Mol Med 33: 978-986, 2014

54. Qu ZH, Yang ZC, Chen L, Lv ZD, Yi MJ and Ran N: Inhibition airway remodeling and transforming growth factor- $\beta 1 / \mathrm{Smad}$ signaling pathway by astragalus extract in asthmatic mice. Int J Mol Med 29: 564-568, 2012.

55. Wang WJ, Yang L, Wang XH and Li HL: Effect of ligustrazine on airway remodeling in asthmatic rats. Zhonghua Jie $\mathrm{He} \mathrm{He} \mathrm{Hu}$ Xi Za Zhi 27: 833-836, 2004 (In Chinese). 